\title{
EL DERECHO PRECOLOMBINO Y EL DERECHO INDIANO Y LAS INVASIONES DE TIERRA
}

Nora Olivero Pacheco

\section{$I$ \\ EL DERECHO PRECOLOMBINO}

EL REGIMEN DE TIERRAS EN EL TAHUANTINSUYO. LA IMPORTANCIA JURIDICA DE LA ASIGNACION DE LAS MISMAS EN EL ROL DE LA AUTORIDAD QUE LO EFECTUO

El estudio del Derecho Precolombino es, de suyo, una ardua y difícil tarea; nuestros antepasados, desafortunadamente, no tenían la costumbre de escribir. Aún cuando existían registros como los quipus, éstos no son inteligibles en la medida de proporcionarnos una cabal información sobre el ordenamiento jurídico, por ejemplo.

De allí que todos los trabajos etno-históricos, son interpretaciones de los testimonios registrados después de la invasión española. Los funcionarios coloniales, que como buenos burócratas eran bien acuciosos, nos han legado su interpretación del sistema normativo incaico. Formados en una cultura de inspiración romanística, en el caso específico de la propiedad de la tierra, recurrieron, como era de esperar, a figuras del Derecho Romano para explicar las instituciones y costumbres que veían.

Así, uno de los puntos de la controversia estaba en establecer si la nuda propiedad era del Inca, correspondiendo el usufructuar a las comunidades (Cobo, 1964 (1653) o, por el contrario, la propiedad era de las comunidades y el usufructo correspondía al Inca (Valera, en: Garcilaso 1960 (1609). Todo esto, claro está, partiendo de la división ternaria tan mentada de Garcilaso (1960 (1609), entre tierra del Inca, tierra del Sol y tierra de las comunidades. 
No vamos aquí a dilucidar las discrepancias de opinión existentes sobre la cuestión de la tierra en el Tahuantinsuyo, sino a extractar elementos de arćlisis que nos permitan realizar la reflexión, objeto de nuestro trabajo.

Veamos en qué consiste la polémica. Mariátegui (1970 (1928) nos plantea la tesis de una propiedad colectiva de la tierra y precisa la existencia de un comunismo agrario. "Al comunismo incaico, que no puede ser negado ni disminuido por haberse desenvuelto bajo el régimen autocrático de los Incas, se le designa por esto como comunismo agrario" (op. cit.: 54). La consideración de "comunismo primitivo" es congruente con la clasificación MorganEngels (1) sobre la evolución de las sociedades; otro contemporáneo, Haya de la Torre (1936), coincide con la tesis del comunismo primitivo de los Incas. Los antecedentes del "primitivismo" que apoyan estas opiniones, podemos remontarlos a Cunow (1929), en su comparación entre el ayllu peruano y la marca germánica; en todos ellos se ubicaba al Tahuantinsuyo poco menos que en el Neolítico.

Baudin (1960 (1928) nos plantea la interpretación de un sistema socialista, donde la propiedad es del Estado -o mejor dicho la nuda propiedad-- en tanto que lo que se concede es el usufructuo. Su énfasis está en la inalienabilidad de la tierra y su distribución periódica; característica esta última de suma importancia como veremos más adelante. Es una solución jurídica a la europea que bien puede encuadrarse dentro del derecho socialista moderno (2).

La división ternaria de Garcilaso (op. cit.) y las analogías con la marca germánica inspiradas en Cunow (op. cit.), parecen ser los

(1) Clasificación de las sociedades basadas en los principios del materialismo dialéctico y que postula una evolución unidireccional a través de los distintos modos de producción.

(2) El derecho socialista moderno tipifica nuevos derechos reales, como el de "administración operacional directa" y "al goce del suelo". Son constituidos por el Estado, actuando como sujeto de derecho público y a través de un acto administrativo. Los titulares de esos derechos pueden oponerlos a terceros, menos al Estado (Ionasco, 1969). 
elementos esenciales que se tratan de integrar en una estructura común. Así se aprecia en Bonilla Arones (1953) y Rostorowski (1962). La tipificación, de clara inspiración romanista, pasa por determinar el carácter colectivo, estatal o privado de la propiedad. No se está tratando de mostrar cómo funcionaba el sistema jurídico incaico, sino explicarlo en términos de nuestro propio derecho; trasponiendo ideas merece mencionarse que el mismo problema nos sucede en nuestros días con los "invasores": estamos pretendiendo interpretar el problema desde "nuestro derecho" y no desde "su derecho".

Murra (1978 (1955), en su primera etapa - ver infra- nos refiere la tenencia de la tierra como relacionada a la estructura de parentescos; no obstante que insiste en la clasificación de tierras bajo diferentes "dominios", sea Inca, individuos, ayllus, panacas $\mathrm{u}$ otros, resaltando nuevamente la importancia de la asignación periódica. Es aquí claro que la tierra se "daba" no se compraba.

En un nuevo enfoque, que se aparta de las líneas del "primitivismo", Moore (1958) realiza un aporte de importancia para comprender el derecho incaico; es probablemente uno de los pocos y más completos trabajos sobre lo que podríamos llamar de esa forma: "derecho incaico". En esencia, el análisis se basa por los tipos de tenencia y los modos de adquisición, en cuanto a lo que a la propiedad se refiere; debemos tener en cuenta que la gradación de los niveles de tenencia es un instrumento de análisis propio del "common law" (3) y que nos aleja del enfoque netamente romanista a que estamos acostumbrados.

Existen, así, dos tipos básicos: tierras tributarias y tierras comunales; paralelamente describe cinco modos de transferncia -o adquisición--: por conquista, por donación del Inca, por herencia, por desplazamiento de ocupación o labor y por redistribución periódica de las tierras comunales. Sin embargo, las distintas tenencias implicaban, distintos derechos y obligaciones tributarias, en forma paralela, por lo que "esta encrucijada de debe-

(3) Mientras el sistema romanístico efectúa un análisis horizontal del derecho de propiedad entre contratantes, el "common law" entre superiores e inferiores. 
res y derechos y el punto en que ellos se entrecruzan con el poder político, proveían la sustentación al sistema Inca de tenencia..." (op. cit.: 47). Si a esto agregamos la inexistencia de multas o sanciones económicas semejantes a daños y perjuicios, porque no había capacidad o posibilidad de acumulación (op. cit.: 76/7), podemos comenzar a pensar en un ordenamiento jurídico bastante diferente al nuestro, en el sentido de estar ausente el concepto de patrimonio.

Sin embargo, con posterioridad a los trabajos citados, continúan las interpretaciones "primitivistas" y romanistas. Así, Godelier (1974) señala "La propiedad del suelo era comunitaria y la tierra era redistribuida periódicamente entre las escasas familias, sin que éstas pudieran transformar ese derecho de uso en derecho de alienación, es decir, en alguna forma de propiedad privada, separada de la propiedad comunal". "Cuando cayeron en la dominación del estado Inca. . . una parte de las tierras fueron expropiadas, convirtiéndose en propiedad del Estado o de la Iglesia". "Las tierras apropiadas por el Estado eran desde entonces trabajadas por cuenta del Estado por los campesinos, sometidos ahora a un régimen de prestación de trabajos" (op. cit.: 177). Estamos aquí en una interpretación actualizada y modernizada de la antigua tesis del comunismo primitivo -ver supra-.

En el caso de Wachtel (1976) la posición es más ecléctica: “. . . en la sociedad inca la propiedad de la tierra no constituye un derecho absoluto; al contrario, es preciso concebirla como una superposición de diferentes derechos. Según las descripciones de Santillán y de Cobo, cuando el Inca conquistaba una provincia, proclamaba sobre el conjunto de las tierras lo que podríamos llamar su derecho eminente, signo de su soberanía". Esto merece, por lo menos dos interpretaciones. Una, es la de suponer el sentido de "derecho eminente", como equivalente al "dominio eminente o directo", propio del derecho feudal; en este caso esa superposición de derechos a que se refiere el autor, tendría su paralelo en la estructura de derechos señoriales y de vasallaje, a distintos grados y niveles, propias del feudalismo europeo. La otra hipótesis que cabría, es suponer que lo que el Inca hacía era afirmar su dominio eminente en el sentido de soberanía y no en sentido patrimonial. Esta última tendría correlación con que "la apropia- 
ción de los bienes en el Imperio, lejos de reducirse a una fórmula simple, muestra entonces el entrecruzamiento de derechos diferentes" (1976: 106).

Esta aparente dicotomía puede aclararse remitiéndose a Rowe (1946), uno de los antecedentes citados por Wachtel (op. cit.). "El ayllu tenía un territorio definido. .." (1946: 255). "De acuerdo con el principio que la tierra pertenecía al grupo de parentesco más bien que a los individuos, estas donaciones especiales de tierra no implicaban propiedad en sentido moderno, sino el derecho a los productos de la tierra (op. cit.: 261). Pero más adelante (op. cit.: 276 y ss.) señala que "el Estado era dueño de la tierra y otorgaba el derecho de uso a las familias, a los grupos de parentesco y ocasionalmente a los individuos". Evidentemente la contradicción que encierran las palabras de Rowe y la ambigüedad de la descripción de Wachtel son índices elocuentes que el asunto no es claro y resulta difícil de tipificar en términos occidentales, sean romanos, del "common-law" o del derecho socialista.

Otra vertiente argumental es la señalada por Katz (1972), resaltando la significación de los sistemas de irrigación y fertilización en un contexto donde, a diferencia de la Europa medieval, la tierra no era propiedad de la nobleza, sino que estaba en posesión del Estado. Además "uno de los rasgos distintivos que hizo diferente esta clase de Estado tan diferente de un Estado esclavista o feudal fue la supervivencia de la organización de parentesco original". No obstante que esta interpretación está más bien orientada al Estado Mochica, destacamos un elemento que se repite en la literatura del tema y se refiere a la significación de la estructura de parentesco. De otra parte, el autor introduce al espacio andino el concepto de sociedad hidráulica, que conduciría a las interpretaciones bajo el esquema del modo de producción asiático (4).

En época reciente, Murra (1960) retoma el problema de la tierra en el Tahuantinsuyo, bajo una tipificación distinta: el "de-

(4) El modo de producción asiático, desarrollo modernamente por Wittfogel (1966), fue aplicado en forma entu siasta en el estudio de los Estados Azteca e Inca. En el caso del mundo andino pueden verse, entre otros, los trabajos de Golte (1978) y Tantalean (1981). 
recho a las tierras". Ya no se habla ni de usufructo, nuda propiedad, "tenancy" u otros conceptos, sino que se trata de analizar bajo conceptos o categorías nuevas. Es que "los derechos a la tierra estaban tan imbricados en la estructura política y social, que hablar de ellos en términos meramente económicos es ineficiente para la futura investigación" (1980: 275). Podemos agregar de nuestra parte que no sólo es ineficiente hablar de los derechos a tierras en términos económicos, sino en los términos jurídicos tradicionales.

Noejovich (1983: 131 ss.) analizando dentro de un contexto de Derecho Romano, postula directamente la inexistencia del derecho de propiedad en el mundo andino precolombino, desarrollando un complicado intento de formalización y categorización que recoge la dualidad del pensamiento andino. En Pease (1986) y Noejovich (1986) se aprecia con mayor claridad el fenómeno de la dualidad de derechos y las hipótesis alternativas de funcionamiento de lo que podemos denominar derecho andino.

Para el primero "después de la invasión española y en medio de la confusión producida por ella, la situación frente a las tierras $u$ otros bienes se hizo visiblemente extralegal, llegando a colocarse al margen de ambos derechos, pero pugnando por ingresar al hispánico. Esta es una consecuencia del hecho colonial en sí, además de que la administración de justicia se encontraba en manos de los colonizadores, quienes dictaban la norma y señalaban el nuevo papel y las limitaciones de la función del curaca" (1986: 7). Desde esta óptica, el curaca era una suerte de administrador de la "tierra de todos", que no era una propiedad colectiva sino "la reunión de los derechos a bienes de los distintos grupos de parentesco que formaban -una unidad étnica y de los distintos linajes dentro de un grupo de parentesco" (op. cit.: 14).

Estamos ante un sistema totalmente diferente al europeo que, como dice Pease "inicialmente, los derechos de los hombres andinos fueron adscritos al Derecho Natural, desde un punto de partida europeocéntrico, pero interesaría mucho comprender las categorias jurídicas existentes en los Andes con aquéllas que no son necesariamente coincidentes con la tendencia romanista dentro de la cual se ubicaba el derecho castellano de la época" (op. cit.: 7). 
Finalmente, y esto es relevante para la situación moderna, "el hombre andino contemporáneo maneja simultáneamente dos nociones de propiedad, una es aquélla proporcionada por el andamiaje jurídico inaugurado con la invasión española del siglo XVI, la otra es la establecida por la relación estrecha con las divinidades que son capaces de hacer producir los bienes de la tierra, la cual, a su vez, es una divinidad" (op. cit.: 24).

Es interesante acotar aquí, que el criterio divino como sustentación del derecho a las tierras es una de las tesis aceptadas en el Africa negra y Madagascar donde, antes de la llegada de los europeos, el derecho de propiedad se considera inexistente (Land Tenure Symposium, 1951 (1940).

Partiendo de hipótesis semejantes, Noejovich (1986) plantea un modelo de funcionamiento del "régimen de bienes" en el Tahuantinsuyo. La relación del sujeto con el objeto es una detentación temporal y condicionada al cumplimiento de un objetivo determinado. Los derechos se sustentan en los vínculos de parentesco, en tanto que el entrecruzamiento de esos derechos es regulado por una autoridad administrativa. Son los señores étnicos, quienes en un plano administrativo asignan la tierra dentro de los parámetros que fijan los derechos basados en el parentesco (op. cit.: 14 y ss.).

En este punto de las investigaciones podemos extraer como conclusión que el "derecho andino" era, definitivamente, diferente al derecho español. Su categorización dentro del derecho natural (ver supra) sirvió de punto de partida al Derecho Indiano que veremos en la sección siguiente. Pero ella explica la nueva normativa sin aclarar la antigua. De lo que sabemos y, aparentemente no se discute, es que, respecto de la "propiedad" o el "régimen de bienes" como lo tipifica Noejovich - ver supra-, es que la sustentación de todo derecho a los mismos pasaba necesariamente por las relaciones de parentesco, fuente y causa de toda obligación y relación jurídica. Como parte de ese sistema la "autoridad étnica" ejercía funciones de regulación de esos derechos; concretamente "asignaba periódicamente las tierras", previa solicitud de los miembros del ayllu. Esa función se reproducía a nivel del Estado, siendo de competencia del Inca efectuar lo que Pease categoriza como 
"donaciones del poder" (op. cit.) y que Polo (1940 (1561) 142) llamó "merced del Inca"; el curaca asignaba tierras a nivel local y el Inca a nivel de Estado. 
EL DERECHO INDIANO

EL REGIMEN DE TIERRAS DE LA CONQUISTA. EL CONCEPTO DE REGALIA DE LA CORONA Y SU ROL DE ASIGNADOR. EL SIGNIFICADO DE LAS MERCEDES Y LAS COMPOSICIONES COMO MODO DE ADQUISICION.

Un buen punto de partida para una imagen histórica del Derecho Indiano, es tomar no sólo en cuenta el derecho proyectado de España a América, sino analizar el conflicto entre éste y el derecho existente aquí (Pease, 1986: 7).

$\mathrm{Y}$ es que en el marco jurídico de la conquista de América primó la idea de respetar el derecho autóctono, en tanto no estuviese en contradicción con los intereses de la Corona. Por ese camino "un nuevo elemento, el representado por las costumbres de los indios sometidos, vino a influir la vida del derecho. .." (Ots Capdequi, 1941: 11).

La metrópoli se proyectó en América, pero a través de las instituciones pre-existentes. Cita Levene (1924: 36), "el gobierno de Toledo en el Perú se presenta como ejemplo de la eficaz utilización de la organización existente, adaptándola y haciéndola servir a los fines de la administración hispánica".

El Derecho Indiano es un derecho mestizo; es un derecho que nace de la praxis, en parte costumbrista, en parte administrativa. Son los funcionarios y miembros de la burocracia que van normando costumbres ancestrales; los problemas, en ocasiones convertidos en litigios, quedan en la órbita meramente administrativa. En otras, continúan la vía judicial hasta las Audiencias y el Consejo de Indias. Como dice Ots Capdequi (1940: 6) "quedaba sólo como verdadero problema, el de la población india, a la cual no podía sometérsele de un modo absoluto a nuestras propias leyes, y el que la ordenación de aquellas cuestiones que la conquista y colonización 
de tierras que constituían un mundo nuevo, planteasen por primera vez. De aquí el carácter casuista de nuestra legislación de Indias...".

Respecto de la tierra y otros bienes los españoles enfrentaron el problema de, por una parte, querer respetar la propiedad de los indios y, por la otra, delimitar ésta para disponer de la vacante. Esta última, comprendida dentro de las "regalías de la corona", como bienes vacantes y mostrencos (Ots Capdequi, 1941: 34) señalaban el espacio que la autoridad española tenía para efectuar los repartimientos de tierra, por lo menos esas eran las intenciones formales.

La propiedad conocida de los indios, fue el problema más espinoso y cuya dificultad de solución dio pie a justificar los abusos cometidos. $\mathrm{Si}$, como hemos visto, el sentido de la propiedad indigena era difuso e incluso inexistente ¿cómo delimitarla? Veamos las preocupaciones de Matienzo (1967 (1567): 57) al señalar que “. . . a cada uno en particular debe darse tantos topos o medidas que sepa y entienda que son suyas y nadie se las ha de poder quitar ni tomar. .." ". . . les viene de mucho provecho, pues esto es lo que les ha de aficionar al trabajo y a ser hombres, y los apartará de la ociosidad, porque hasta aquí no han poseido tierras propias antes del cacique se las reparte como él quiere".

Buen ejemplo para mostrar el conflicto. El oidor preconiza el establecimiento de la propiedad privada y rechaza la función de asignación del curaca; por un lado vemos cómo el derecho de propiedad, en el sentido español, no existe y, por otro, vemos cómo la función del señor étnico no se comprende.

Desde los inicios, la corona se esforzó por mostrar su respeto a la propiedad conocida de los indios. Así en el requerimiento de 1513 , destinado a leerse a los aborígenes de las tierras que acaban de descubrirse, se les promete que "vos dejaremos vuestras. . haciendas libres y sin servidumbre" (Mariluz Urquijo, 1978: 24). También en la temprana limitación a la facultad de enajenar de los indios, en prevención de los abusos, como se comprueba en una Instrucción del 20 de Marzo de 1503 (Ots Capdequi, 1940: 116). Además, la Recopilación de Leyes de Indias señala: "que a los in- 
dios se les dejen tierras. .. con sobra todas las que le pertenecieren, así en particular, como por comunidades, $\mathbf{y}$ las aguas, $\mathbf{y}$ riegos; . . ." (Ley 18, tit. 12, lib. 4. En: Ots Capdequi, 1940: 114).

El otorgamiento de mercedes, de importancia radical en la formación de los dominios territoriales durante la colonia, contenía una cláusula concebida en estos términos, aproximadamente: "la cual merced él hacía e hizo siendo sin perjuicio de los naturales y siendo con perjuicio sea visto no serla hecha dicha merced". El estudio del alcance y naturaleza juridica de dicha cláusula indicaría su carácter de condición resolutoria de la merced (Mariluz Urquijo, op. cit.: 26).

Las mercedes de tierras pueden ser consideradas como un modo de adquisición legítimo en Derecho Indiano; no eran una mera ocupación -aun cuando podía comenzar con ella-, sino una adquisición de un título válido en términos. Si la "propiedad" de los indios y la ocupación por los españoles pueden adscribirse al derecho natural, la merced debe adscribirse al derecho civil.

La Corona española, en el más puro sentido romanista, se reservó los privilegios sobre los territorios conquistados. El reconocimiento de la llarnada "propiedad de los indios" es parte del ejercicio de ese privilegio, es el príncipe, dueño de todos los territorios por derecho de conquista que acepta a sus súbditos y les permite conservar sus posesiones.

Con esa concepción, pre-existente al descubrimiento mismo de América, el instrumento juridico que reglaba las relaciones entre la Corona y los conquistadores era la capitulación. Este contrato entre las partes, reconocía, generalmente, el derecho a otorgar mercedes.

Una Real Cédula de 1591 declaraba que eran de "patrimonio y Corona Real el Señorio de los Baldios, suelo y tierra" que no había sido ya concedidos y que "era su voluntad - la real-el que con ellos se recompensara y favoreciera a las ciudades y a los habitantes, tanto indios como españoles de aquellos territorios". Se ordenó, además, a todos los poseedores la exhibición del título en cuya virtud se poseia, revirtiendo a la Corona las que no lo fueran 
a justo título, para repartirlas nuevamente; esta doctrina concuerda con la Recopilación de las Leyes de Indias (Ley 14, tit. 12, lib. 2. En: Ots Capdequi, 1940: 15).

Queda así claro el concepto de regalía de la Corona que postulara Solórzano Pereira (1972 (1642), de donde la tierra sin dueño $-\mathrm{y}$ los bienes mostrencos- pertenecían a la Corona, es decir eran "realengas". Con la Real Cédula de 1591 de Felipe II, la Corona reafirma su derecho a otorgar tierras, que en el periodo de conquista anterior, estaba delegado $\multimap$ cedido, según interpretaciónal conquistador con quien se efectuó la capitulación. Reconocida la propiedad indígena -ver supra - a partir de ese momento bajo la autoridad real, se organiza formalmente el reparto de tierras; esta autoridad, obviamente se ejerce en forma delegada a través de los Virreyes, Gobernadores, Audiencias y Cabildos. Estos últimos tuvieron especial significación en el otorgamiento de mercedes, ya sea por acción directa, ya sea como "asesores" de las Audiencias e Intendencias (Mariluz Urquijo, op. cit.: 34 ).

La disposición acerca del justo título contenida en la Real Cédula antes citada tiene algunos aspectos que destacar. En primer lugar es un antecedente importante para el requisito confirmación de la merced. Se discute si este requisito es un formulismo o no (Mariluz Urquijo, op. cit.), pero el hecho que fuera recogida en la Recopilación de las Leyes de Indias (Ley 16, título XIl, Libro IV), arroja una idea a la evolución doctrinal el sentido que tenía la confirmación, en tanto reafirmación del derecho del príncipe sobre la tierra realenga, cuya merced se otorgaba en su nombre.

El segundo aspecto importante de resaltar es netamente doctrinario y se refiere a la interpretación del justo título frente al tiempo de ocupación. Sabido es que el otorgamiento de la merced exigía el requisito de residencia, ya que era un privilegio de los conquistadores; había que estar en posesión so pena de perderla. Por ello las interpretaciones doctrinales de Solórzano (op. cit.) y León Pinelo (1922) hacen hincapié en el tiempo de posesión, más largo el primero -40 años -- y más corto el segundo -5 años-.

Es así que puede considerarse, también, que la merced estaba sujeta a la condición de la ocupación de la tierra (Mariluz Ur- 
quijo, op. cit.: 54). (Ots Capdequi, 1940:43). Posesión y dominio -entendido por el título- aparecen como dos requisitos indisolubles para el perfeccionamiento del derecho, al menos en los primeros tiempos de la Colonia.

Finalmente, paralelamente a la Real Cédula de 1591 -ver supra- se dictó otra que permitía pagar a la Corona una compensación en lugar de restituir la tierra poseída sin justo título.

Esta disposición "que se repartiesen tierras y las que estaban repartidas, con menos legítimos títulos de los que convenía, se compusiesen" (León Pinelo op. cit.) tiene claros orígenes fiscales. Sin embargo, desde un punto de vista jurídico es una vía de saneamiento del título de propiedad. Por supuesto que se mantenía el requisito de posesión, aun cuando el tiempo de la misma podía graduarse ateniendo a circunstancias como que la merced le faltaba la confirmación o los deslindes no correspondían a la merced original (Mariluz Urquijo, op. cit.: 61); es decir, cubría desde la posesión de mala fe hasta las imperfecciones de "trámite". Al decir de Konetzke (1978: 42) ". . . lo usual era disimular tal delito de propiedad y considerarlo prescrito. ..", mediante el pago de compensaciones de tierras.

La adquisición por compra, no fue la más significativa en los tiempos de la Colonia. Algunas veces las tierras eran adquiridas por subasta pública en lugar de "componerlas" a través del procedimiento antes citado. La compra venta entre particulares se rigió por el Derecho español y la única disposición significativa -0 conjunto de tales- se refieren a las prohibiciones de los indios de enajenar las suyas, salvo a los propios indios.

Esto nos permite extraer una conclusión importante para nuestro objetivo. El modo de adquisición por excelencia fue la merced, entendida como dádiva de la autoridad, aun cuando el carácter de dádiva es discutible, toda vez que, en una u otra forma se "componía". O sea, que un sistema era invadir y luego componer. Aquí, la autoridad que otorga originariamente la merced juega un rol decisivo como asignador de tierras, ya que el trámite ulterior consiste en obtener la confirmación o sanear el título, vía la composición. 
En ese sentido, la capacidad de peticionar ante las autoridades no era sólo prerrogativa de los españoles, ya que los indios también solicitaban tierras o mercedes y utilizaron los instrumentos jurídicos de Derecho Indiano al igual que los españoles (5).

(5) Un ejemplo interesante son los pedimentos de Jerónimo Gaucrapaucar, cacique Huanca a la Audiencia de Lima (Espinoza Soriano, 1971). También hay ejemplos de la conducta indígena temprana en los protocolos de Moquegua publicados por Pease (En: Masuda, 1984). 


\section{III}

\section{LAS INSTITUCIONES PRECOLOMBINAS Y COLONIALES COMO ANTECEDENTE DE LAS INVASIONES DE TIERRA}

La comparación de los dos sistemas expuestos, muestra de primera intención, cuál es el punto central en la articulación de los mismos: el rol de la autoridad.

En el caso del Derecho andino, la autoridad étnica o, si se quiere, étnica y política, era la asignadora de las parcelais. En el Derecho Indiano, también era la autoridad que, principalmente, asignaba las tierras; la diferencia aparente en el rol de las dos autoridades eran los móviles de cada una y fundamentalmente la existencia de una economia monetaria.

Pongamos que ambos casos, la autoridad es la encargada de asignar las tierras. En el caso del Derecho Indiano existía una forma de "forzar" esa asignación a través de la composición. Mientras uno -el curaca - lo hacía como obligación ancestral hacia su gente, donde el "deber ser" nacía de los compromisos de parentesco, el otro -el Cabildo - lo hacía en cumplimiento de sus deberes de funcionarios, en quien la instancia superior delegaba su derecho; en este caso, además podía intervenir un factor pecuniario.

Otra distinción importante, la da el contexto social. Para el hombre de los Andes, la tierra es parte de su ser, no se concibe hombre sin tierra (Arguedas y Ortiz Rescaniere, 1965); el español podía admitir en su sociedad, hombre sin tierras, lo que, por otra parte, era frecuente en virtud a la institución de los mayorazgos.

Aun cuando las motivaciones de fondo hayan sido totalmente diferentes, lo cierto es que ambos mundos, la autoridad administrativa es fundamental para originar el derecho de propiedad. Importante coincidencia que, como veremos, tiene vigencia en nuestros días. 
Los recientes títulos de propiedad emitidos por la Municipalidad de Lima son un claro ejemplo. Podemos admitir que la Municipalidad actual, hace las veces de Cabildo de antaño; asimismo que las asociaciones vecinales formadas por los "invasores" son las peticionantes, ¿qué es lo que peticionan? Una auténtica merced de tierras, como en los tiempos coloniales.

¿Pero por qué la invasión como antecedente a la petición? Es muy sencillo. La concepción ancestral no admite que el individuo no tenga tierra, que no tenga techo; no concibe que la autoridad se lo niegue porque esa es su obligación: ASIGNAR TIERRAS.

Por otra parte, siempre tratándose de terrenos eriazos, éstos están reivindicados a favor del Estado, por los mismos principios doctrinales de Solórzano -ver supra-, por el cual los bienes vacantes y mostrencos eran de la Corona; principio corroborado, como hemos visto, por las Reales Cédulas de 1591 -ver supra-. Allí, fue donde chocaron antaño las dos culturas y es allí donde chocan también ahora.

En efecto, en términos de derecho andino, su "derecho a acceso a tierras". que es natural y por el derecho de nacer (Guamán Poma, 1980 (11:15: 1136), sólo puede estar limitado por otros nacidos que ocupen tierras antes, bajo el mismo derecho; en este caso las tierras vacías, que no tienen ocupante, no son de nadie y son del común, ya que esas tierras vacías son las que asegurarán la continuación de la especie. Por ello, la invasión es el ejercicio de un derecho que la autoridad administrativa -versión moderna del jefe étnico-deberá con seguridad convalidar. En términos de derecho indiano, del cual somos herederos, la autoridad estaría en condiciones de otorgar mercedes sobre tierras vacantes. Sin embargo, nuestro ordenamiento legal no contempla adecuadamente este punto.

Los "títulos" emitidos por la Municipalidad de Lima son meramente "en armonía con los criterios señalados por los Ministerios de Justicia y Vivienda, aprobados por D.S. No. 038-82 JUS", ¿En qué consiste esa armonía? ¿se le delegó autoridad, como lo hacia el Rey de España, para obtener mercedes? 
el lote revierte a la Municipalidad, es decir, se lo quitan.

Amén de lo folklórico del procedimiento, es interesante destacar cómo aparece la figura de la confirmación. Si bien en forma harto ambigua, el requisito de inscripción en los Registros, de imposible o difícil consecución, indica que, alguna autoridad superior, que el emitente no precisa, deberá otorgar la escritura requerida por nuestro derecho registral. O sea, se reconoce la existencia de una autoridad que debe confirmar la merced. El retener el derecho a revertir lo que se otorga, sería también un índice que la confirmación es un requisito indispensable para el perfeccionamiento del acto.

El asunto es que el Derecho Indiano tenía un procedimiento para sanear estas cuestiones, incluso vía la composición, el que podía ser lento, pero las solucionaba. Nuestro derecho más moderno no tiene, aparentemente, procedimiento alguno $\mathrm{y}$, antes bien, sanciona como delito las invasiones (6). Es evidente, a mi juicio, que legislar a espaldas de la realidad histórica y social solo sirve para mantener los conflictos. Esto es, quizá uno de los resultados del espíritu liberal del siglo XIX que inspira la mayor parte de Códigos Latinoamericanos; como si la simple implementación de un sistema jurídico hubiera sido la solución.

Con referencia correcta a las invasiones, los españoles fueron indudablemente más pragmáticos. Su legislación, el Derecho Indiano, fue casu ística, porque comprendieron que enfrentaban pueblos con costumbres distintas. Nuestros legisladores, educados en doctrinas europeas, romanistas, germanas o anglosajonas, pretenden transplantar instituciones en vez de crearlas por interpretación de la costumbre. A semejanza de otras regiones del orbe, como el Africa, por ejemplo, nuestro derecho es esencialmente "costum-

(6) El D.L. No. 14495 , art. 3, encuadra las invasiones dentro del art. 283 del C.P. No distingue si las tierras fuesen públicas o privadas. Sin embargo, a pesar de esas sanciones, las invasiones en Lima tienen una larga y casi "honorable historia" (Dietz, 1977: 378). 
brista". Desde ese punto de vista, la legislación debería hacer norma la costumbre y no tratar de modificarla imponiendo normas distintas o abiertamente contradictorias.

La gente invade porque cree tiene su derecho a tierra y que no tiene obligación de comprarlo, sino es obligación de la autoridad el dárselo. Así funcionaban sus antepasados y así, en cierta medida, se adaptaron los españoles a través del Derecho Indiano.

Después de todo, la invasión no es más que una ocupación y ésta era una forma de adquisición también en Derecho Romano. No hay de extraño que a través de la figura de la merced, su confirmación y, quizá, su composición, apoyados en el derecho ancestral andino que asegura a cada familia su parcela, podamos construir un sistema normativo ágil e inteligible que elimine los numerosos conflictos planteados. 
ARGUEDAS, José María y ORTIZ RESCONIERE, Alejandro

1965 La posesión de la tierra, los mitos prehispánicos, la visión del universo en la población monolingüe quechua. En: Los problemas agrarios de América Latina. CNRS, París.

BAUDIN, Louis

1960 (1928) El Imperio Socialista de los Incas. Santiago: ZigZag.

BONILLA ARONES, Angel

1953 La propiedad territorial indígena en el Perú. Tesis, PUC, Lima.

COBO, Bernabé

1964 Historia del nuevo mundo. Madrid: Biblioteca de Autores Españoles.

CUNOW, Heinrich

1929 El sistema de parentesco peruano y las comunidades gentilicias de los incas. Lima.

DIETZ, Henry

1977 Land Invasion and Consolidation: Astudy of working poor/governmen tal relations in Lima, Perú. Institute of Latin American Studies, 195, off print series, U.T. Austin.

ESPINOZA SORIANO, Waldemar

1971 Los huancas aliados de la conquista. Anales de la Universidad del Centro. Huancayo.

1978 Los modos de producción en el Imperio de los Incas. (Compilador) Lima: Mantaro.

GARCILASO DE LA VEGA, Inca

1960 (1609) Comentarios Reales de los Incas. Madrid. Biblioteca de Autores españoles. 
GOLTE, Jürgen

1978 La economía del Estado inca y la noción de modo de producción asiático. En: Espinoza Soriano, 1978 .

GODELIER, Maurice

1974 Economía, fetichismo y religión en sociedades primitivas. Mexico: siglo XXI.

GUAMAN POMA DE AYALA, Felipe

1980 (1615) Primera nueva corónica y buen gobierno. México; Siglo XXI

HAYA DE LA TORRE, Victor

1936 El antiimperialismo y el apra. Santiago.

IONASCO, Trajan

1969 Considerations generales sur la notion du droit de propiete socialiste. En: Noejovich, 1986.

KATZ, Friedrich

1972 Ancient american civilizations. New York: Praeger.

KONETZKE, Richard

1978 América Latina: La época colonial. Madrid: Siglo $\mathrm{XXI}$.

LAND TENURE SYMPOSIUM

1951 (1940) Universidad pers Leiden. Leiden.

LEON PINELO, Antonio de

1922 Tratado de las confirmaciones reales. Buenos Aires.

LEVENE, Ricardo

1924 Introducción a la historia del derecho indiano. Buenos Aires: El Ateneo.

MARIATEGUI, José Carlos

1979 (1928) 7 ensayos de interpretación de la realidad peruana. Lima: Amauta. 
MARILUZ URQUIJO, José M.

1978 El régimen de la tierra en el derecho indiano. Buenos Aires: Abeledo Perrot.

MASUDA, Shozo (Ed.)

1984 Contribuciones a los estudios de los andes centrales. Universidad de Tokio.

1986 Etnografia e historia del mundo andino: continuidad y cambio. Universidad de Tokio.

MATIENZO, Juan

1967 Gobierno del Perú. París-Lima: Insttitut Francais d'Estudes Andines.

MURRA, John M.

1978 (1955) La organización económica del estado inca. México: siglo XXI.

1980 Derecho a las tierras en el Tahuantinsuyu. Revista de la Universidad Complutense de Madrid. Vol. XXVIII, No. 117.

MOORE, Sally F.

1958 Power and Property in Inca Perú. Columbia University, New York.

NOEJOVICH, Héctor Omar

1983 La economia andina en el entorno de la conquista española. Tesis, PUC, Lima.

1986 El Régimen de bienes en la América Precolombina $y$ el hecho colonial. Ponencia al VII Symposium de Historia Económica, CLACSO - IEP, Lima.

O'TS CAPDQUI, José María

1940 El derecho de propiedad en nuestra legislación de indias. Estudios de Historia del Derecho Español en las Indias, Bogotá: Minerva.

1941 El estado español en las indias. México: FCE.

PEASE Franklin

1984 Libro notarial de Moquegua (presentación). En: Masuda, 1984. 
1986 La noción de propiedad entre los incas: una aproximación. En: Masuda, 1986.

POLO DE ONDEGARDO

1940 (1561) Informe del Licenciado Polo de Ondegardo al Licenciado Briviesca de Muñatones. Revista Histórica, T. 13, Lima.

ROWE, John H.

1946 Inca Culture at the Time of the Spanish Conquest, Handbook of South American Indians. T. 2. Washington D.C.: Smithsonian Institution.

ROSTOROWSKI DE DIEZ CANSECO, $M$.

1962 Nuevos datos sobre tenencias de tierras reales en el Incario. Revista del Museo Nacional, 131, Lima.

SOLORZANO PEREIRA, Juan de

1972 (1642) Politica Indiana. Madrid: Biblioteca de Autores Españoles.

TANTALEAN, Javier

1981 Modo de producción asiático, Estado y sociedad Inca. Histórica, V, No. 1.

VALERA, Blas

1960 (1609) En: Garcilaso de la Vega, 1960.

WACHTEL, Nathan

1976 Los vencidos. Madrid: Alianza.

WITTFOGEL, Karl

1966 Despotismo oriental. Madrid: Guadarrama. 